\title{
Sistemas eleitorais e partidáriosः Duverger, Sartori e Nohlen
}

Bruno Rangel Avelino da Silva ${ }^{1}$ (Universidade de Brasília, Brasil)

bruno@rangelferreira.adv.br

SIG, quadra 01, lote 495, Ed. Barão do Rio Branco, sala 17

Brasília, DF. CEP 70-610-410

1. Mestre em Direito pelo Centro Universitário de Brasília - UniCeub (2011). Professor na Faculdade de Direito da Universidade de Brasília - UnB. Professor nos cursos de pós-graduação em Direito Eleitoral do Instituto Brasiliense de Direito Público - IDP e da Universidade Federal do Tocantins - UFT. Membro fundador da Academia Brasileira de Direito Eleitoral e Político - ABRADEP. Integrante do Grupo de Pesquisa registrado no CNPQ - Observatório do Direito Eleitoral, vinculado à Universidade do Estado do Rio de Janeiro - UERJ. Advogado sócio do escritório Rangel Ferreira Advogados. 


\title{
Resumo
}

São corriqueiras as propostas de alterações no sistema eleitoral com objetivo de diminuir fragmentação partidária para atribuir maior governabilidade à Chefia de Governo. Nessa perspectiva, o presente estudo busca verificar se o sistema eleitoral possui efeitos diretos sobre o sistema partidário, de forma a moldá-lo. Para tanto, é trazido diálogo entre Maurice Duverger, Giovanni Sartori e Dieter Nohlen.

Palavras-chaveः Sistemas Eleitorais, Sistemas Partidários, Partidos Políticos.

\section{Party representation: Between internal democracy and autonomy}

\begin{abstract}
Usually changes are discussed in the electoral system in an attempt to resolve any problems caused by fragmentation in Congress party to allow head of Government more governance. From this perspective, this study intends to verify whether the electoral system has direct effects on the party system in order to shape it. Therefore, dialogue is brought between Maurice Duverger, Giovanni Sartori and Dieter Nohlen.
\end{abstract}

Keywords $¥$ Electoral Systems, Party Systems, Political Parties. 
O presente artigo discorre sobre ponto de partida teórico para análise das relaçóes entre sistema eleitoral e sistema partidário, a partir da afirmação de que um sistema eleitoral pode comparar-se a um freio ou um acelerador, sendo que um tipo de sistema eleitoral favorece a multiplicação de partidos que outros tipos de sistema dificultam ${ }^{293}$. Tal afirmação é fértil quando se argumenta, por exemplo, pela necessidade de adoção de fórmulas majoritárias para escolha de Deputados Federais como forma de diminuir o número de partidos representados. Importante notar que a alteração no sistema eleitoral pode trazer efeitos diversos, sendo relevante avaliar se no caso brasileiro pode ser notada relação de causa e efeito entre sistemas eleitorais e partidários.

Importante notar que na sua interação com os sistemas partidários, os sistemas eleitorais podem representar: (i) relação de causa e efeito; (ii) fator que exerce maior ou menor influência a depender da realidade local, porém não determinante; (iii) fator que exerce função irrelevante sobre o sistema partidário. Para avaliação de tais hipóteses é utilizado diálogo não contemporâneo, mas ainda atual entre Maurice Duverger, Giovanni Sartori e Dieter Nohlen.

\section{Ponto de partida: Os enunciados sociológicos de Duverger}

O diálogo que se propóe trazer no presente artigo é iniciado a partir dos seguintes enunciados de Duverger:

(i) sistema eleitoral com fórmula de representação proporcional conduz a um sistema pluripartidarista com partidos rígidos, estáveis e independentes (exceto no caso de movimentos repentinos);

(ii) sistema eleitoral com fórmula de representação majoritária absoluta, com segundo turno, tende a um pluripartidarismo com eleições flexíveis, dependentes e relativamente estáveis (em todos os casos);

(iii) sistema eleitoral com fórmula de representação majoritária relativa, conduz a um bipartidarismo com partidos grandes e independentes que se alternam.

Importa dizer que Duverger realizou tais formulações em 1951, já com advertências no sentido de que o esforço do trabalho então desenvolvido visava romper com o círculo até então existente e trazer uma primeira teoria geral dos partidos políticos, necessariamente vaga, conjectural e aproximativa, que pudesse servir de base para futuras e mais profundas análises. Ressaltou que o livro pretendia tentar explicar hipóteses suscetíveis de guiar futuras investigações que permitiriam formular, um dia, autenticas leis sociológicas. ${ }^{294}$

Destaque-se que até aquele momento a maior parte dos estudos acerca dos partidos políticos envolvia análises de suas doutrinas, tratando de aspectos muito mais sociológicos em torno dos grupos políticos que formavam os partidos do que sobre a própria estrutura partidária e os seus efeitos jurídicos e políticos. Consta que o primeiro estudo aprofundado sobre

293. DUVERGER, Maurice. Los partidos politicos. México: Fondo de Cultura Económica, 2006.

294. DUVERGER, Maurice. Los partidos políticos. México: Fondo de Cultura Económica, 1996. 
a estrutura organizacional dos partidos políticos foi lançado em 1902, por Moisei Ostrogorski $^{295}$, e, até o início dos anos 1950, quando Duverger lançou sua obra aqui tratada, apenas outro trabalho mais sistemático foi publicado, o de Robert Michels, em $1911^{296}$. O próprio Duverger, em 1951, ressaltou esse ponto, ao afirmar que, "deixando de lado essas duas obras, não existe nenhum estudo comparativo das estruturas partidárias" ${ }^{297}$.

Consequentemente, a importância do tema e a escassez de estudos e de modelos mais profundamente desenvolvidos até aquele momento fizeram com que o texto de Duverger assumisse, desde logo, a posição de uma obra teórica e metodológica fundadora de um relevante marco de pesquisa. Portanto, sua ascensão quase imediata ao status de clássico deveu-se, principalmente, às inovações analíticas importantes trazidas pelo autor à área dos estudos partidários. ${ }^{298}$

É oportuno dizer que tal autor não classificou os enunciados como leis, mas sim de fórmulas ou esquemas, não obstante tais fórmulas terem ficado conhecidas como "as leis de Duverger" ${ }^{299}$. Note-se que Duverger tratou de três formas de representação, quais sejam: (i) fórmulas majoritárias de turno único; (ii) fórmulas majoritárias de dois turnos e; (iii) fórmulas proporcionais.

Pode-se dizer que os efeitos das duas primeiras - fórmulas majoritárias com único turno e com dois turnos -, quando comparados entre si, tendem a ser bastante diversos (a primeira tenderia ao bipartidarismo e a segunda ao pluripartidarismo), contudo, no tocante à comparação entre a segunda e a terceira - fórmula majoritária com dois turnos e fórmula proporcional - a distinção não é tão claramente visível, eis que as duas tendem ao pluripartidarismo, registrando o autor que em quase todos os países o sistema de dois turnos cedeu lugar ao da representação proporciona ${ }^{300}$. Ainda assim, Duverger entende importante a diferenciação para verificar qual o grau de influência de cada sistema.

A abordagem acerca dos enunciados acima será iniciada no presente artigo pela terceira formulação, qual seja: "O sistema de maioria relativa conduz a um bipartidarismo com partidos grandes e independentes que se alternam", pode-se dizer que de acordo com Duverger, a relação entre sistema de maioria relativa de turno único e o resultado bipartidarismo, está baseada em dois fatores quais sejam: "fator mecânico" e "fator psicológico". 301

O fator mecânico deve-se ao fato de que, naturalmente, o sistema de maioria relativa que elege os partidos mais votados em apenas um turno -, possui tendência a dificultar a participação efetiva dos partidos minoritários na disputa eleitoral, o que não tende a ocorrer no

295. Trata-se da obra: OSTROGORSKI, Moisei. La démocratie et l'organisation des partis politique. Paris: Calmann-Levy, 1903.

296. Trata-se da obra: MICHELS, Robert. Trad. TREVISAN, Hamilton. Os partidos políticos. São Paulo: Senzala, 1969.

297. PERES, Paulo. Revisitando a teoria geral dos partidos de Maurice Duverger. Revista Brasileira de Informação Bibliográfica em Ciências Sociais - Anpocs 68.2. São Paulo, 2009, p. 17-58.

298. Ibidem.

299. SARTORI, Giovanni. Engenharia constitucional: como mudam as constituições. Brasília: UnB, 1996, p. 42.

300. DUVERGER, Maurice. Los partidos políticos. México: Fondo de Cultura Económica, 1996, p. 269. Ver também em: BALDINI, Gianfranco. PAPPALARDO, Adriano. Elections, electoral systems and volatile voters. Hampshire: Palgrave Mcmillan, 2009, p.102-115.

301. Ibidem. 
caso do sistema proporcional tendo em vista que o seu objetivo é, justamente, proporcionar efetiva participação de grupos minoritários no Poder.

Dessa maneira, o efeito mecânico ocorre quando um terceiro partido que participa da disputa majoritária em turno único, não alcance número de assentos proporcional à votação obtida, tendo em vista a forte tendência no sentido de que apenas dois partidos maiores conquistem a maior parte das cadeiras. Por exemplo: Suponha que um terceiro partido aqui denominado "partido C" possui votação bastante expressiva em todo o país, mas não conseguiu mais votos do que os outros dois partidos "A" e "B" em nenhuma das circunscriçóes, embora tenha chegado perto. Conclui-se do resultado, quem embora tendo obtido votação bastante expressiva, os votos a ele atribuídos se perderam para fins de representação por mandatos.

Exemplos gritantes desse fenômeno podem ser encontrados na história eleitoral dos países que adotam esse sistema eleitoral. É o caso do Reino Unido, onde nas eleições de 2015 o United Kingdon Independence Party conquistou 12,6\% do total de votos e obteve apenas uma vaga, embora tenha obtido votação percentual maior do que a de outros partidos que conquistaram mais assentos ${ }^{302}$.

Tal constatação é resultante do fato de que a eleição por maioria relativa adotada em circunscrições uninominais corresponde a várias eleições isoladas. Diante disso, um terceiro partido, ainda que consiga um número razoável de votos em cada circunscrição, pode passar próximo de conquistar número significativo de mandatos, mas não conseguir estar representado, de forma que o seu apoio de nada lhe servirá se não obtiver a maioria dos votos ${ }^{303}$, configurando, assim, o "fator mecânico".

É oportuno destacar que o fator mecânico nem sempre ocorrerá, tendo em vista a possibilidade de acontecer o contrário, ou seja, de vários partidos conquistarem cadeiras em cada uma das circunscrições, na hipótese de não existirem dois partidos com maioria em todas as circunscrições, situação em que estarão representados vários partidos que obtiveram poucos mandatos e, neste caso, a depender da relevância de cada partido no sistema, seria encontrado um quadro pluripartidário e não bipartidário, como consta no enunciado.

No Brasil, país com grande desigualdade econômica e com variações ideológicas regionais não parece razoável crer que a adoção de fórmulas eleitorais de maioria relativa em único turno fosse capaz de gerar um sistema bipartidário, ou mesmo com poucos partidos. A dualidade de forças é completamente distinta em cada um dos Estados. Não foi por outra razão que a ideia de verticalização das coligações partidárias em nível nacional e estadual não foi bem recepcionada por grande parte da classe política. Portanto, as posições diferentes em cada um dos distritos tende a fazer com que, nestes casos, a representação majoritária não conduza a um bipartidarismo nacional. Merece observar também que no caso brasileiro o número de partidos representados possui causas concorrentes, tal como a maior ou menor intervenção do Poder Judiciário de modo a favorecem ou restringir a criação de partidos. ${ }^{304}$

302. Disponível em: <http://www.electionresources.org/uk/house.php?election=2015>. Acesso em 23.11.2015.

303. SILVA, Luis Virgílio Afonso da. Sistemas eleitorais. São Paulo: Malheiros, 1999, p. 110.

304. Vale destaque o recente julgamento de liminar na ADI 5105, onde restou afirmado que o parlamentar que migra para partido novo leva junto tempo de TV e fundo partidário proporcional à votação obtida pelo infiel. Tal fator favorece o aumento do número de partidos representados, sem relação direta com os sistemas eleitorais. 
Duverger chega a tratar dessa questão ao estabelecer que "esse sistema [majoritário em turno único] pressiona incontestavelmente na direção do dualismo de partidos; pelo menos no interior de cada circunscrição eleitoral; mas os dois adversários podem ser diferentes nas diferentes regióes do país" ${ }^{\prime 35} \mathrm{e}$, portanto, pode não se verificar um quadro de bipartidarismo no parlamento após o resultado geral das eleições. Todavia, ainda que cada circunscrição possua características próprias, defende o autor que seria possível dizer que um sistema bipartidário poderia surgir, uma vez que a adoção de fórmula majoritária de turno único tenderia a gerar o efeito de destruir, de forma progressiva, os partidos pequenos e médios, deixando a competição eleitoral apenas para os dois maiores partidos, configurando o fator mecânico. ${ }^{306}$

Acerca do fator psicológico se trata do chamado voto útil, segundo o qual os eleitores, em uma eleição majoritária em turno único, evitam votar em um terceiro partido que não aparente possuir chances de vitória para afastarem-se do sentimento de que estariam jogando fora $o$ seu voto. Com efeito, caso esteja evidente para o eleitor que apenas os dois partidos grandes têm reais chances de eleger o representante do distrito, é comum que o eleitor prefira deixar de lado o partido de sua preferência para votar em um dos dois que possuem chances reais de saírem vencedores, fortalecendo-os cada vez mais e diminuindo, por outro lado, as chances de um terceiro partido ocupar lugar efetivo na disputa eleitoral. ${ }^{307}$

Portanto, para Duverger esse regime eleitoral - majoritário de turno único - inegavelmente conduz ao bipartidarismo. Todavia, faz ressalvas no sentido de haverem outros fatores capazes de influenciar o sistema partidário e, com estas reservas, afirma que se pode considerar o bipartidarismo como resultante do escrutínio majoritário de turno único. ${ }^{308}$

No tocante à segunda lei sociológica, qual seja: "O sistema de maioria com segundo turno tende a um pluripartidarismo com eleições flexíveis, dependentes e relativamente estáveis" ${ }^{\text {"309. }}$. Neste caso, Duverger afirma ser mais difícil precisar a relação de causalidade. Importante dizer que o autor atentava para o fato de que quando da publicação de seus estudos, havia número limitado de dados empíricos acerca das eleições parlamentares com segundo turno. Contudo, ainda assim seria possível estabelecer a tendência de se verificar como resultado de eleiçóes majoritárias com segundo turno a ocorrência de multipartidarismo. Tal tendência decorria do fato de que no primeiro turno os eleitores sentiam-se livres para votar no partido de sua preferência, sendo este o momento em que diversos partidos surgem com chances de vitória.

Assim, apenas no segundo turno, ocorreriam os efeitos "mecânico" e "psicológico", conservando aos demais partidos as chances de obter maior número de cadeiras no primeiro turno. Nos dizeres do autor, a observação empírica, embora restrita até aquele momento, mostrou que quase todos os países com segundo turno são igualmente multipartidaristas ${ }^{310}$. A França adotou tal critério eleitoral após 1958 quando a fórmula proporcional foi substituída pela

305. DUVERGER, Maurice. Los partidos políticos. México: Fondo de Cultura Económica, 1996, p. 254.

306. Ibidem.

307. Ibidem.

308. Ibidem, p. 255.

309. Ibidem.

310. DUVERGER, Maurice. Los partidos políticos. México: Fondo de Cultura Económica, 1996, p. 267. 
fórmula majoritária com dois turnos ${ }^{311}$ (embora já tivesse utilizado essa fórmula durante a III República). É a fórmula que vem sendo utilizada até o presente momento (deixou de ser utilizada apenas de julho de 1985 a julho de 1986). Assim, a série de eleições francesas pós1958, parece confirmar o que Duverger avaliou anos antes. ${ }^{312}$

Por outro lado, não obstante a presença de vários partidos verifica-se, por exemplo, que nas eleiçóes parlamentares francesas de $2012^{313}$, os 577 assentos no parlamento formam distribuídos entre treze partidos, sendo que os dois maiores alcançaram respectivamente 280 (Parti Socialiste) e 194 assentos (Union pour un Mouvement Populaire), os demais 103 assentos foram distribuídos entre os onze demais partidos.

Nas eleições parlamentares de 2007 chegou-se a constatação semelhante, sendo que os 577 assentos foram distribuídos entre onze partidos, sendo que os dois maiores alcançaram respectivamente 313 (Union pour un Mouvement Populaire) e 186 (Parti Socialiste) e os demais 78 lugares distribuídos entre dos nove partidos restantes. Algo parecido ocorreu em 2002, demonstrando uma sequência histórica que parece confirmar, no caso francês, que um sistema majoritário de dois turnos pode conduzir a um multipartidarismo. Todavia, para os autores que classificam os sistemas partidários não apenas de forma numérica, mas pelo grau de relevância dos partidos, o sistema francês é classificado entre os casos bipartidarismo imperfeito. ${ }^{314}$

Com relação à primeira lei sociológica de Duverger, qual seja, "a representação proporcional conduz a um sistema pluripartidarista com partidos rígidos, estáveis e independentes (exceto no caso de movimentos repentinos)", o autor, embora faça ressalvas quanto ao fato de o enunciado representar uma tendência, atribui à representação proporcional o efeito multiplicador dos partidos políticos, ao dispor que "o efeito multiplicador [da representação proporcional] é incontestável"., 315

Ao discorrer sobre o tema, Duverger diferencia mencionada tendência ao multipartidarismo, gerada pelo sistema de representação proporcional, em três aspectos: (i) a representação proporcional mantém uma multiplicidade existente; (ii) favorece a cisão no interior dos partidos, porque as frações dissidentes, ainda que pequenas, poderão conquistar mandatos; (iii) estimula ou facilita a criação de novos partidos.

Diversos autores procuraram averiguar a validade das proposiçóes de Duverger por intermédio de testes empíricos. Arend Lijphart ${ }^{316}$ após examinar diversas democracias chegou à conclusão de que dois casos eram excepcionados: o Canadá e a Áustria. Como o Canadá utiliza a representação majoritária simples para eleger os cargos da Câmara Baixa, o mais provável é que tivesse um sistema bipartidário. Contudo, o Canadá possuía um sistema de dois

311. HANCOCK, Donald. M. Politics in Europe. Washington, D.C: CQ Press, 2007, p. 139-140.

312. PACTET, Pierre. Institutions politiques droit constitutionnel. Paris: Armand Colin, 2002, p. 101.

313. Disponível em: <http://www.electionresources.org/fr/deputies.php?election=2007\&region=FR>. Acesso em 23. nov. 2015.

314. GRUNBERG, Gérard. HAEGEL, Florence. Le bipartisme imparfait en France et en Europe. Revue internationale de politique comparée, 2007/2 Vol.14, p. 325-339. Disponível em: <http://www.cairn.info/ revue-internationale-de-politique-comparee-2007-2-page-325.htm>. Acesso em 23. nov. 2015.

315. DUVERGER, Maurice. Los partidos políticos. México: Fondo de Cultura Económica, 1996, p. 281.

316. LIJPHART, Arend. Modelos de democracia: desempenho e padrões de governo em 36 países. 2. ed. Rio de Janeiro: Civilização Brasileira, 2008, p. 99 e 192-193. 
partidos e meio, com dois grandes partidos (Liberal e Conservador) e um terceiro partido, médio (Partido da Nova Democracia).

Nas eleições para o parlamento canadense de 2015, a exceção parece se confirmar, caminhando o Canadá mais em direção ao pluripartidarismo do que ao bipartidarismo. Como se observa, em 2015 os resultados demonstraram a existência de um sistema pluripartidário, com poucos partidos. Das 338 cadeiras em disputa, 184 foram conquistadas pelo Liberal Party of Canada, 99 pelo Conservative Party of Canada, 44 pelo New Democratic Party, 10 pelo Bloc Québécois e 1 pelo Green Party of Canada. ${ }^{317}$

O mesmo país, nas eleições de 2011, apresentou quadro semelhante, sendo que das 308 cadeiras, 166 foram conquistadas pelo Conservative Party of Canada, 103 pelo New Democratic Party, 34 pelo Liberal Party of Canada, 4 pelo Bloc Québécois e 1 pelo Green Party of Canada. Assim, o Canadá se apresenta, de fato, como exceção ao enunciado de Duverger, já que não apresenta quadro bipartidário embora adote fórmulas de maioria relativa de turno único. ${ }^{318}$

A Áustria também foi mencionada como exceção pelo fato de que embora se caracterizasse por uma representação proporcional, não apresentava quadro pluripartidário. Entendia-se que haviam apenas dois partidos expressivos (Social Democratic Party of Austria e Austrian Peaple's Party $)^{319}$. Ocorre que tal constatação só se confirmou até as eleições de 2002. A partir das eleições de 2006 se percebeu a existência de outras duas forças relevantes (Freedom Party of Austria e The Greens), sendo que nas eleiçóes, realizadas em 2013, as 183 cadeiras foram distribuídas da seguinte maneira: 52 ao Social Democratic Party of Austria, 47 ao Austrian Peaple's Party, 40 ao Freedom Party of Austria, 24 ao The Greens, 11 ao Team Stronach e 9 ao The New Austria. ${ }^{320}$

Tais dados demonstram que a Áustria, se já fez, atualmente não faz parte das exceções aos enunciados de Duverger de representação proporcional conduzindo ao pluripartidarismo. Ainda mais pelo fato de que são apenas 183 cadeiras no parlamento, divididas atualmente entre seis partidos, demonstrando quadro de grande fragmentação partidária.

Registre-se que o caso brasileiro enquadra-se no enunciado de Duverger já que vislumbra-se representação proporcional e quadro multipartidário, embora se possa admitir que o sistema proporcional talvez não seja a única razão para o desenho partidário no Brasil. Consta que nas eleições de 1998 a Câmara dos Deputados brasileira contou com 18 partidos representados na Câmara dos Deputados. Nas eleições de 2002 foram 16 partidos representados, em 2006 eram 20 partidos, em 2010 existiam 22 partidos e em 2014 foram 28 partidos representados - tomando por base a data da posse. ${ }^{321}$

Verifica-se que de fato o sistema partidário brasileiro é altamente fragmentado, com várias bancadas numericamente expressivas, possuindo a maior bancada apenas 69 dos 513

317. Disponível em: <http://www.electionresources.org/ca/house.php?election>. Acesso em: 23. nov. 2015.

318. Idem.

319. NICOLAU, Jairo Marconi. Multipartidarismo e democracia. Rio de Janeiro: Fundação Getúlio Vargas, 1996, p. 43.

320. Disponível em: <http://www.electionresources.org/at/nationalrat.php?election=2013\&land=> . Acesso em: 23, nov. 2015.

321. Disponível em: <http://www2.camara.gov.br/deputados/liderancas-e-bancadas/bancada-na-posse > Acesso em 23. nov. 2015. 
assentos. Dessa forma, a par dos fatores históricos e sociais, pode-se dizer que a observação empírica enquadra o Brasil entre os países que adotam fórmula e arranjos proporcionais e tem como resultante um sistema multipartidário, embora se reconheça forte carga das decisóes do STF sobre o desenho do quadro partidário.

\section{As críticas de Sartori e os novos enunciados apresentados}

Os debates acerca das relaçóes entre sistemas eleitorais e partidários ocorreram ao longo do tempo, de modo que ainda na década de 60 , outros autores como Douglas $\mathrm{Rae}^{322}$ se dedicaram a comprovar a aplicação dos enunciados de Duverger por meio de análises empíricas. Rae, por exemplo, submeteu a primeira lei de Duverger (sobre os efeitos do sistema majoritário) a um teste de correlação, segundo o qual de 107 casos, 89,7\% recaem na categoria de associaçóes previstas. Rae comenta que isso "sugere uma relação um pouco mais fraca do que poderia sugerir a expressão lei sociológica". ${ }^{323}$

Após ter se dedicado por anos aos estudos sobre o tema, na década de $80 \mathrm{Sartori}^{324}$ definitivamente publica suas críticas aos enunciados apresentados por Duverger e classificados pela doutrina enquanto leis sociológicas. Sartori apresenta outras possíveis combinações, mas entende que os sistemas eleitorais teriam efeito direto sobre os sistemas partidários.

De acordo com Sartori, os enunciados paradigmas de Duverger admitiriam que uma relação causal poderia ser provada por uma correlação, não fazendo distinção entre "ser a causa de" e "estar associado a". Em segundo lugar, uma generalização causal só pode ser verificada se causa e efeito forem claramente especificados; o que não acontece com o efeito da primeira lei (o dualismo partidário), enquanto o efeito da segunda (multipartidarismo) sofre também de excessiva imprecisão. A questão é que as leis que postulam efeitos sobre o número de partidos existentes precisam explicar como esse número de partidos é determinado. ${ }^{325}$

Sartori conclui, portanto, que Duverger não segue regra consistente, sendo que em algumas hipóteses específicas ele trata dos partidos nominalmente e, em outras vezes, deixa de considerar alguns destes partidos por serem semi-partidos, partidos locais ou presumivelmente efêmeros. Dessa maneira, como o efeito da causa que se presume ocorrer nunca é determinado, Duverger poderia "modelar sua evidência de modo a que pareça confirmar a lei proposta. E, mesmo assim, suas leis sofrem muitas exceções". ${ }^{326}$

Ainda assim, mesmo considerando que as leis de Duverger podem ser facilmente rejeitadas, Sartori as trata como relevante objeto de estudo, de forma que, segundo ele, a maioria dos autores que se dedicaram ao estudo das mencionadas leis sociológicas dão-se

322. RAE, Douglas. Leyes electorales y sistema de partidos políticos. Madrid: Citep, 1997.

323. Ibidem.

324. SARTORI, Giovanni. Engenharia constitucional: como mudam as constituições. Brasília: Unb, 1996.

325. Ibidem.

326. Ibidem. 
por satisfeitos em demonstrar o engano de Duveger. Todavia, Sartori se propõe a dar continuidade ao estudo das leis sociológicas, abordando o próprio conceito de lei, para, ao final, apresentar novas proposições. ${ }^{327}$

Destaca que quando se trata de ciência social, as "leis" compreendem generalizações dotadas de poder explicativo que detectam uma regularidade. Nesse contexto, a idéia de "poder explicativo" torna-se crucial, ao passo que fundamenta a diferença entre leis científicas e leis estatísticas. No tocante a estas últimas, pode-se dizer que quantificam freqüências confirmadas, mas não tem "poder explicativo". Dessa forma, saber quanto tempo vive uma pessoa, por exemplo, não explica coisa alguma. Assim, a respeito do poder explicativo, temos que, quanto maior esse poder, mais definida a relação causa-efeito estabelecida por uma lei, exigindo-se dela mais do que generalizações e constatações. ${ }^{328}$

Além disso, Sartori destaca que, tendo em vista que uma lei é aceita como tal até ser refutada, a lei deve ser formulada de modo que permita sua confirmação ou refutação por meios empíricos. Assim, a fundamental diferença entre as leis é o que elas se propõem a prever, se eventos singulares ou apenas classes de eventos. Dessa maneira, nas ciências sociais a maioria das leis não prediz eventos singulares, mas classe de eventos, de maneira estatística. No entanto, espera-se que as leis a respeito da influência dos sistemas eleitorais - a causa - sobre o número de partidos políticos - o efeito - apliquem-se a todos os eventos eleitorais e a cada um deles. ${ }^{329}$

Em conseqüência, a abordagem de Sartori concentra-se no estudo das exceçóes, as quais já haviam sido constatadas por Douglas Rae. É nesse sentido que Sartori destaca que, naturalmente, se é possível admitir que uma lei é determinista - dada a causa é também dado o efeito - bastará uma única exceção para refutá-la.

Mas, nas ciências sociais as leis não podem ser e nunca são determinísticas, admitindo, portanto, certo desvio. No entanto, ainda que uma lei não-determinística não possa, por isso mesmo, ser desmentida por suas exceções (desde que sejam realmente exceções), "tais exceções tornam-se perturbadoras e propõem um enigma”. Segundo Sartori, este pode ser tratado de dois modos: a) introduzindo uma condição necessária que restrinja a aplicabilidade da lei (de modo que a exceção deixe de ser tal); ou b) incorporando a exceção numa reformulação da lei. ${ }^{330}$

Dessa forma, com base nas diretrizes acima, Sartori se propôs a prosseguir no estudo das mencionadas leis sociológicas, no intuito de apresentar novas leis, mais restritivas, que pudessem admitir um menor número de casos excepcionais. Ademais, ao admitir a possibilidade de falharem as leis formuladas e, nesta hipótese, persistirem as exceçóes, Sartori entende que só neste caso é que se pode concluir que a lei foi debilitada, embora não desmentida por tais exceções, tendo em vista não ser determinística.

Nesse contexto, embora tenha feito severas críticas às leis sociológicas de Duverger, Sartori termina por reiterar a influência dos sistemas eleitorais sobre os sistemas partidários. Com efeito, destaca que os sistemas eleitorais têm um duplo efeito - sobre o eleitor e sobre o número de partidos. Afirma que tais efeitos merecem ser avaliados separadamente, porque o número de partidos não deriva apenas do comportamento dos eleitores, mas também do

327. SARTORI, Giovanni. Engenharia constitucional: como mudam as constituições. Brasília: Unb, 1996.

328. Ibidem.

329. Ibidem.

330. SARTORI, Giovanni. Engenharia constitucional: como mudam as constituições. Brasília: Unb, 1996. 
modo como os seus votos são transformados em assentos na representação parlamentar sistemas eleitorais. ${ }^{331}$

O efeito sobre os eleitores é descrito geralmente como restritivo, observando que esse efeito varia de fortemente restritivo - nos sistemas majoritários - a completamente não-restritivo - na representação proporcional pura. Quanto ao último caso, o sistema eleitoral não teria qualquer efeito. Dessa forma, Sartori entende que o impacto do sistema eleitoral sobre o número de partidos possui efeito redutivo, qualquer que seja o sistema eleitoral, pois ou o seu número é reduzido ou o sistema eleitoral se tornaria ineficaz. Assim, esclarece não haver efeito multiplicador e que o mencionado efeito redutor varia de forte a fraco, destacando, ainda, que o problema de como contar o número de partidos mostra-se de extrema relevância, tendo em vista ser enganosa a contagem numérica de todos os partidos de um determinado sistema partidário.

Assim, antes de formular as suas "leis" Sartori fixa premissa no sentido de que as referências relacionadas aos sistemas partidários com dois, três, quatro, cinco ou mais partidos, dizem respeito a partidos relevantes, identificados pelas regras de contagem que levam em consideração o valor substantivo dos partidos. Assim, Sartori traça o argumento acerca das suas novas leis que pretendem estabelecer relações de causalidade entre os sistemas eleitorais e os sistemas partidários iniciando pelos sistemas com fórmulas majoritárias.

O autor igualmente trata do exemplo do distrito uninominal eleito pela fórmula majoritária: neste caso a escolha do eleitor é limitada aos candidatos mais importantes - a não ser que prefira desperdiçar o seu voto. Assim, trata-se de sistema eleitoral que produz, no interior de cada circunscrição, competição entre dois partidos. Mas se o eleitor é pressionado, no distrito onde vota, a uma dupla escolha, não se pode concluir que haja redução correspondente do número de partidos nacionais. Dessa maneira, o efeito limitativo sobre os eleitores não é o mesmo efeito exercido sobre o número de partidos ${ }^{332}$. A razão para tal constatação diz respeito ao fato de que em cada circunscrição eleitoral há uma eleição isolada das demais.

Dessa forma, conclui-se que nenhuma fórmula majoritária pode, isoladamente, conduzir o país a um bipartidarismo, ou a uma redução significativa no número de partidos representados, a não ser que os dois ou pouco partidos relevantes o sejam em todas as circunscriçóes, fato que manteria uma regularidade nos resultados eleitorais em favor dos mesmos partidos relevantes em cada uma das circunscrições. Assim, para Sartori o problema se coloca no sentido de estabelecer de que forma o bipartidarismo local se transforma em bipartidarismo estadual ou nacional, informando que falta uma condição necessária ao argumento de que a eleição por maioria relativa tende ao bipartidarismo, concluindo que tal condição necessária é o próprio sistema partidário. ${ }^{333}$

Com efeito, destaca que o que condiciona o eleitor não é apenas o sistema eleitoral, mas também o sistema partidário. Dessa forma, os efeitos do sistema eleitoral sobre o sistema de partidos - e não sobre os eleitores - não podem ser avaliados corretamente sem uma avaliação simultânea da estrutura do sistema partidário quanto à sua força - fortemente estrutu-

331. Ibidem.

332. SARTORI, Giovanni. Engenharia constitucional: como mudam as constituições. Brasília: Unb, 1996, p. 50.

333. Ibidem. 
rado ou fracamente estruturado ${ }^{334}$. Nesse sentido, os sistemas que apresentam fórmulas majoritárias somente possuem influência, além da circunscrição - quando há sistema partidário estruturado nacionalmente. Importa registrar que Sartori se importa em dizer que os autores que negam o efeito redutor das fórmulas majoritárias "se referem a sistemas partidários desestruturados, contestando, assim, uma "lei" em situações em que a lei não é aplicável. ${ }^{335}$

Além disso, Sartori discorre sobre a possibilidade de estabelecer, sob a forma de leis, a influência dos sistemas eleitorais sobre os sistemas partidários, estabelecendo quatro de regras descritivas, para adiante, chegar à formulação das suas "leis". Nesse sentido, a primeira regra estabelecida informa que um sistema baseado fórmula majoritária não pode, por si mesmo, produzir um formato bipartidário em escala nacional, mas em quaisquer circunstâncias ele ajudará a manter um sistema bipartidário já existente. Portanto, sempre que se estabelecer um formato de dois partidos, o sistema de pluralidade exerce uma influência moderadora e tem um efeito de "congelamento".

A segunda regra destaca que no longo prazo, um sistema majoritário produzirá o formato de dois partidos (mas não a eternização dos mesmos partidos) sob duas condiçóesः a primeira, que o sistema partidário seja estruturado; a segunda, que o eleitorado, refratário a qualquer pressão do sistema eleitoral, esteja disperso pelos vários distritos em proporção abaixo da pluralidade.

Inversamente, a terceira regra demonstra que um formato bipartidário é impossível - sob qualquer sistema eleitoral se minorias raciais, lingüísticas, ideologicamente alienadas, centralizadas em um tema ou de outra forma incoercíveis (e que não podem ser representadas por dois partidos de massa) se concentrarem em proporção acima da pluralidade em bolsóes geográficos localizados ou em certos distritos eleitorais. Se a situação for essa, o efeito do sistema de pluralidade só será redutivo com relação a um terceiro partido que não represente minorias inconciliáveis.

Já a quarta e última regra demonstra que os sistemas de representação proporcional também mostram efeitos redutivos, embora em escala menor escala, particularmente quando funcionam em circunscrições eleitorais pequenas. Nessas condições a representação proporcional também eliminará os partidos menores cujo eleitorado esteja disperso por vários distritos. Mas mesmo a representação proporcional com elevado grau de impureza não eliminará os pequenos partidos que dispóem de bases com concentração acima da quota.

Dessa maneira, Sartori formula quatro enunciados substitutivos das leis de Duverger, quais sejam:

1. Dado um sistema partidário estruturado e com dispersão uniforme de votos entre os distritos (ambas condições necessárias), sistemas majoritários por maioria simples causam (são condições suficientes para) um formato bipartidário;

1.1. alternativamente, um sistema partidário com estrutura particularmente rígida é, sozinho, a substitutiva condição necessária e suficiente para causar um formato bipartidário;

334. Entende-se por sistema partidário não estruturado aquele em que o eleitor não se identifica com a figura do partido, mas apenas com personalidades. Por outro lado, identificam-se sistemas partidários estruturados quando os partidos conseguem se colocar diante do eleitor como imagem abstrata, sendo percebido como um sistema natural de canalização política da sociedade.

335. SARTORI, Giovanni. Engenharia constitucional: como mudam as constituições. Unb: Brasília, 1996, p. 50 . 
2. Dado um sistema partidário estruturado, mas não havendo dispersão uniforme dos votos entre os distritos, os sistemas majoritários por maioria simples causam (são uma condição suficiente para) a eliminação dos partidos que estejam abaixo da maioria relativa, mas não impedem, e portanto, permitem tantos partidos acima de dois, quantos quanto for permitido pela concentração acima da maioria relativa;

3. Dado um sistema partidário estruturado, a representação proporcional obtém um efeito redutor causado (como condição suficiente) pela sua não-proporcionalidade prática. Assim, quanto maior a impureza da representação proporcional, maiores serão os custos para a representação dos pequenos partidos, e mais forte será o efeito redutor; e, inversamente, quanto menor for a impureza, mais fraco será esse efeito.

3.1. Alternativamente, uma estrutura partidária particularmente rígida é, sozinha, condição necessária e suficiente para manutenção de qualquer sistema partidário pré-existente à introdução do sistema proporcional;

4. Não existindo estruturação partidária e presumindo uma representação proporcional pura, isto é, um custo igual de representação para todos os partidos, o número de partidos poderá ser tão grande quanto for permitido pelo quociente eleitoral.

Note-se que, mesmo após todo o esforço empreendido para diferenciar causa, condição necessária e condição suficiente, aparentemente Sartori utiliza condição suficiente como sinônimo de causa. Além disso, duas condições que, na primeira parte da primeira lei, eram necessárias para que o fenômeno do bipartidarismo ocorresse, foram, na segunda parte, substituídas por apenas uma. Dessa maneira, se a distribuição uniforme dos votos era uma condição necessária para a existência de bipartidarismo e, ainda assim foi substituída, nos demonstra não parecer tão necessária assim, o que esvazia o poder explicativo de suas leis. ${ }^{336}$

Outro aspecto relevante das formulações de Sartori é que o autor insere como fato relevante o grau de estruturação do sistema partidário, o qual poderia sustentar qualquer sistema partidário existente antes da adoção de fórmulas proporcionais.

\section{As conclusões de Dieter Nohlen acerca das formulações de Maurice Duverger e Giovanni Sartori}

Outro autor que se dedicou e ainda se dedica ao exame do tema é Dieter Nohlen, que na década de 90 cuidou de publicar os seus estudos críticos acerca dos enunciados que pretendem estabelecer relações de causa e efeito entre os sistemas eleitoral e partidário. Ao contrário de Duverger e Sartori, para Nohlen, os sistemas eleitorais possuem posição relevante, mas não determinam a formação dos sistemas partidários. Tal autor contribuiu para o estudo do problema, trazendo diversos outros elementos, não presentes no sistema eleitoral e que também podem determinar o modelo partidário.

336. SILVA, Luís Virgílio Afonso da. Sistemas eleitorais. São Paulo: Malheiros, 1999, p. 115. 
Nohlen explica que as deficiências encontradas nas leis sociológicas se encontram em três âmbitos, quais sejam: (i) empírico; (ii) teórico; (iii) metodológico. Assim, os problemas empíricos residem nas leis que atribuem aos três tipos básicos de fórmulas de representação efeitos que não são verificados em um grande número de casos. Com efeito, diversos casos contradizem os efeitos das leis atribuídas aos tipos básicos de sistemas eleitorais (majoritários com um turno, majoritários com dois turnos e proporcional). ${ }^{337}$

Tais casos são, por exemplo, os países que adotam fórmulas de representação de maioria relativa e, no entanto, possuem sistemas pluripartidários, tal como o Canadá e, além disso, países que adotam sistemas de representação proporcional e, no entanto, são bipartidários. A Áustria era citada como exemplo ${ }^{338}$, afirmação que atualmente merece os reparos anteriormente descritos. Entretanto, até esse ponto, tais exceçôes foram identificadas também por Duverger e Sartori, os quais, cada um ao seu modo, tratou da possibilidade de ocorrência de casos excepcionais.

Ocorre que, para Nohlen, o fato de existirem repetidas exceções, faz perceber que as leis encontram-se formuladas inadequadamente, porque não indicam sobre quais condições deveriam produzir efeitos. Logo, os casos excepcionais não foram reconhecidos ou bem utilizados para aperfeiçoar as leis. É interessante destacar que a crítica inicial de Sartori também era nesse sentido, no entanto, finalizando os seus argumentos, termina por formular novos enunciados, um pouco mais específicos, mas que também não afastaram os casos excepcionais.

Ademais, para o autor, as leis sociológicas falham também no ponto de vista teórico, tendo em vista que existindo exceções para as supostas relaçóes causais entre os sistemas eleitorais e partidários, seria necessário especificar em que condições possíveis têm validade tais leis. Assim, a formulação clássica das leis não considera os casos excepcionais de forma a utilizar-los para aperfeiçoar as fórmulas.

Quanto às falhas em relação ao método, Nohlen destaca que as análises feitas para formulação das leis, não comparam um sistema eleitoral com outro, mas sim o sistema de maioria relativa em circunscrições uninominais com um princípio de representação: o da representação proporcional. Todavia, este princípio pode se transformar em múltiplas formas de sistemas eleitorais, que podem produzir efeitos muito diversos. ${ }^{339}$ Assim, seria possível, em casos específicos, a adoção de fórmulas majoritárias ou mistas em conjunto com o princípio de representação proporcional.

Segundo Nohlen, Sartori tem aproveitado as críticas às leis de Duverger para reformular tais leis de forma mais suave, em que a tendência e não o determinismo se encontre mais presente: A primeira lei dispóe que:

\footnotetext{
337. NOHLEN, Dieter. Sistemas electorales y partidos políticos. 3. ed. México: Fondo de Cultura Económica, 2004, p. 431.

338. NOHLEN, Dieter. Sistemas de partidos: in Diccionario electoral. San José: Instituto Interamericano de Derechos Humanos, 1989, p. 645.
}

339. Idem. Sistemas electorales y partidos políticos. México: Fondo de Cultura Económica, 2004, p. 432. 
as fórmulas eleitorais majoritárias facilitam (são condições que facilitam) um formato bipartidário e, inversamente, obstruem (são condições, que obstruem) o multipartidarismo. A segunda lei dispõe que: As fórmulas eleitorais de representação proporcional facilitam o multipartidarismo e, inversamente, dificilmente conduzem a um bipartidarismo. ${ }^{340}$

Nessa forma atenuada, os enunciados por certo se cercam de condições e observações empíricas, no entanto, não desaparecem as debilidades estruturais, tais como condições gerais de aplicabilidade. Por outro lado, Sartori esforçou-se, principalmente, em indicar as condições concretas para tratar dos sistemas eleitorais, de tal forma que possam manter-se as leis sociológicas, formulando outras quatro leis sociológicas. ${ }^{341}$

Como visto, introduziu condições em que os efeitos das leis poderiam ser verificados. A primeira variável é a existência de partidos estruturados em condiçóes de se tornarem partidos de massas, já que no caso existirem partidos não estruturados, os sistemas de partidos são pouco sensíveis aos efeitos que possam decorrer dos sistemas eleitorais. A segunda variável é a distribuição geográfica do eleitorado dos partidos.

Em primeiro lugar se comprova que as quatro leis estão em diversos níveis explicativos. Verifica-se, por exemplo, que a quarta lei de Sartori, em comparação com as outras três, não constitui propriamente uma lei, conforme informado pelo próprio Sartori, no sentido de que tal enunciado representa apenas uma explicação. ${ }^{342}$

Nohlen critica as leis de Sartori também pelo fato de que estão formuladas de tal forma a serem consideradas deterministas e não poderem fracassar jamais. Ou seja, não podem apresentar nenhum outro resultado que não seja o previsto nas formulaçóes. Para Nohlen, tal conclusão é verificada de forma mais clara quando as leis de Sartori são expressas em outras palavras, da seguinte maneira:

Lei n. 01 - Se nenhum terceiro partido - além dos dois grandes - alcança a maioria relativa dos votos em uma circunscrição eleitoral, existe um sistema bipartidário;

Lei n. 02 - Se estão presentes terceiros partidos (quer dizer, outros além dos dois grandes) que alcançam maiorias relativas em uma circunscrição eleitoral uninominal, existem tantos partidos, além de dois, quanto possa exibir essa concentração geográfica de votos.

Lei n. 03 - Quanto mais forte for o efeito de desproporção do sistema eleitoral - neste caso, do sistema proporcional - mais forte será o efeito de redução do número de partidos, ou, formulando brutalmente: quanto menos passem pela barreira da circunscrição.

340. NOHLEN, Dieter. Op.cit., p. 645.

341. NOHLEN, Dieter. Sistemas de partidos: in Diccionario electoral. San José: Instituto Interamericano de Derechos Humanos, 1989, p. 645.

342. Ibidem. 
Destaque-se que tais enunciados não se mostram incorretos, todavia, se entende que o seu conteúdo informativo é reduzido ${ }^{343}$. Entende que o conteúdo é reduzido pelo fato de que leva em conta exclusivamente a interação entre os sistemas eleitorais (com seus elementos tais como fórmula eleitoral, distribuição das circunscrições e estrutura do voto, por exemplo) e os sistemas partidários, sem levar em consideração outros elementos encontrados fora do âmbito do sistema eleitoral, mas que também podem influenciar na formação do sistema partidário.

Além disso, Nohlen trata do entendimento de Duverger - sistema majoritário conduz a um bipartidarismo e a representação proporcional a um multipartidarismo -, aduzindo que, nas leis de Sartori, a explicação é limitada, não só por causa das condiçóes assinaladas, mas também em razão dos elementos presentes na própria sistemática eleitoral, no sentido de que para Sartori, os sistemas eleitorais sempre possuem efeito redutor do número de partidos, efeito que pode aumentar conforme a impureza da representação proporcional presente no sistema eleitoral. ${ }^{344}$

Além disso, ao analisar os outros dois autores, Nohlen informa que tendo em vista o fato de que a maioria dos sistemas eleitorais proporcionais não provoca uma proporcionalidade pura de sufrágios e mandatos, se modificaria completamente o enunciado das leis apresentadas - o marco da conceituação da relação entre fórmulas majoritárias e proporcionais de Sartori - no sentido de que duas causas elaboradas dicotomicamente não conduzem mais a dois resultados diferentes. ${ }^{345}$

Portanto, é o caso de diferenciar os diferentes tipos de efeitos dos sistemas eleitorais, quais sejam: (i) efeito direto e; (ii) efeito indireto. Nesse sentido, o efeito direto dos sistemas eleitorais reside na transformação de votos em mandatos. Assim, os sistemas eleitorais dão forma às preferências políticas mediante o voto. Influem na votação na medida em que colocam os eleitores frente a uma situação decisória específica marcada por diferentes possibilidades de êxito de candidatos e partidos. Dessa forma, o eleitor é afetado pelo sistema eleitoral e impulsionado a estruturar o seu voto segundo as condiçóes apresentadas. Além disso, ao passo que os sistemas eleitorais convertem votos em mandatos, este é o critério empírico para medir os efeitos diretos dos sistemas eleitorais. ${ }^{346}$

Se por um lado existe bastante evidência empírica e certeza sobre a relação entre os diferentes elementos do sistema eleitoral tais como: a magnitude das circunscrições eleitorais, forma de listas, métodos de cálculo, cláusulas de barreira, entre outros, e o grau de proporcionalidade. Por outro lado, a relação entre votos e mandatos é complexa, dado que, por exemplo, sistemas proporcionais puros podem falhar em seu propósito e sistemas não puros superar-lhes em grau de proporcionalidade ${ }^{347}$ Caberia ao eleitor decidir, em última instância, decidir quantos partidos serão representados.

Quanto ao efeito indireto de dois sistemas eleitorais temos que estes influem na quantidade e no formato dos sistemas de partidos. Corresponde a definição dos tipos básicos, sendo

343. NOHLEN, Dieter. Sistemas de partidos: in Diccionario electoral. San José: Instituto Interamericano de Derechos Humanos, 1989, p. 645.

344. Ibidem.

345. Ibidem.

346. NOHLEN, Dieter. Sistemas de partidos: in Diccionario electoral. San José: Instituto Interamericano de Derechos Humanos, 1989, p. 645.

347. Ibidem. 
que as fórmulas majoritárias fomentam mais vigorosamente do que a representação proporcional, a formação de um partido com a maioria dos assentos. Também nos sistemas proporcionais se favorece ao partido maior, não obstante o princípio de representação não tender a isso. Dessa forma, Nohlen entende que não existe nenhum enunciado científico sustentável e que contenha um alto nível de informação sobre os efeitos causados pelos sistemas eleitorais que pudesse se desprender completamente das variáveis históricas e sociais.

Dentre tais variáveis estariam a homogeneidade ou heterogeneidade social, étnica, cultural, religiosa, política, e a estrutura do sistema de partidos, por exemplo. Assim, Nohlen destaca que existem muito menos evidências empíricas e certeza a respeito da relação entre sistemas eleitorais e sistema de partidos políticos, tendo em vista que os efeitos diretos (sobre o eleitor) e indiretos (sobre o sistema partidário) resulta do caráter diferente de cada variável em estudo. Quanto mais se aproximam do âmbito matemático, maior previsibilidade e, quanto mais se aproximam do campo histórico e político, menor previsibilidade, ressaltando, ainda, que em geral se confundem os dois campos de investigação. ${ }^{348}$

Assim, o autor conclui seus argumentos no sentido de que o sistema eleitoral é produto da evolução histórica e sua variação resulta do fato de que não pode ser considerado fora de contexto histórico, mas sim mediante a observação de que foi desenvolvido como reflexo das estruturas sociais em situações específicas de cada país. Ademais, os efeitos políticos dos sistemas eleitorais dependem em grande medida destas estruturas sociais, de condições institucionais e comportamentos políticos, tornando-se imprescindível analisar sempre as condições específicas de cada país para que se possa prever qual será a estrutura do sistema partidário. ${ }^{349}$

Além do mais, os dois tipos básicos de fórmulas eleitorais são a eleição majoritária e a representação proporcional que se distinguem pelo princípio de representação resguardado, a saber: desproporção de votos e mandatos a fim de facilitar a formação de maiorias no Parlamento ou relação proporcional entre votos e mandatos buscando facilitar a representação proporcional de grupos sociais. Somente é possível fazer poucas afirmações gerais sobre os efeitos das eleições majoritárias e das proporcionais, sendo assim, a tese é contrária a todos os ensaios de criar ou determinar leis sociológicas sobre os efeitos políticos dos sistemas eleitorais. ${ }^{350}$

Ademais, não existiria enunciado cientificamente sustentável e de alto conteúdo informativo acerca dos efeitos dos sistemas eleitorais que podem desprender-se completamente das respectivas relaçóes sociais e políticas. A homogeneidade ou heterogeneidade social, étnica ou religiosa de uma sociedade é muito mais importante para a estrutura de um sistema partidário do que as relaçóes entre sistemas eleitorais e partidários de maneira descontextualizada da história. Tal contexto é altamente relevante para a adoção de determinado sistema eleitoral. Portanto, o sistema eleitoral exerce influência sobre o sistema de partidos, mas não é o único fator que o determina. ${ }^{351}$

348. Ibidem.

349. NOHLEN, Dieter. Sistemas eleitorais: o contexto faz a diferença. Lisboa: Livros Horizonte, 2007, p. 56.

350. NOHLEN, Dieter. Sistemas electorales y partidos políticos. México: Fondo de Cultura Económica, 2004, p. 127.

351. CARTER, Elisabeth. FARRELL, David. M. Electoral systems and election management. In: NORRIS, Pippa. LeDUC, Lawrence. NIEMI, Richard G. Comparing democracies: elections and voting in the 21 Century. Los Angeles: Sage, 2010, p. 33. 
Assim, a partir do relevante debate entre tais autores acredita-se como razoável a seguinte constatação: a maior fragmentação social conduz à implantação de um sistema proporcional, sendo mais favorável ao surgimento de um multipartidarismo. Quando há maior predomínio de homogeneidade social, tende-se a optar pela fórmula de maioria relativa, mas ainda que se decida por uma fórmula proporcional, será possível verificar um sistema bipartidário ou um pluripartidarismo limitado.

Registre-se, ainda, que os efeitos dos sistemas eleitorais dependem, além disso, de seus diversos elementos e da forma como estes se combinam. Não há que se analisar somente esse nível global de sistema eleitoral, mas também deve ser levado em conta como se relacionam os diferentes elementos constitutivos do sistema, sendo imprescindível a definição de cada um dos elementos para estabelecer relações causais entre eles. Ademais, os efeitos de um sistema eleitoral dependem muito de verificar se os partidos respondem às condições de êxito implícitas no sistema eleitoral. ${ }^{352}$

Vejamos que a mudança das condições objetivas (por exemplo, fatores sócio-estruturais), e das condiçóes subjetivas (por exemplo, atitudes funcionais ou do eleitorado) produz variações nos efeitos do sistema eleitoral. Não existe um sistema eleitoral perfeito, existindo somente soluçóes técnicas e politicamente mais aceitáveis que outras para países diferentes, em épocas distintas. Em consequência, parece estar mal colocado o problema acerca do melhor sistema que dominou durante muito tempo a literatura especializada. Ainda quando existir um sistema eleitoral ideal, tal escolha se dará em decorrência da decisão de forças políticas que atuam na tomada de decisão, assim, a questão do sistema eleitoral é uma questão de poder. ${ }^{353}$

Por outro lado, vale constar que existem autores que tendem a aceitar uma relação de causalidade entre sistemas eleitorais e sistemas de partidos, todavia, em sentido contrário do que foi proposto por Duverger, ou seja, com o sistema partidário determinando o sistema eleitoral e não o contrário. Nesse sentido, seriam os partidos que, visando a maximização das suas chances eleitorais, é que definiriam qual o sistema eleitoral mais adequado ao cumprimento desta finalidade. ${ }^{354}$

\section{Conclusões}

A formulação das leis sociológicas, iniciadas por Duverger, são úteis e podem funcionar como ponto de partida para a discussão acerca de qual o sistema pode melhor se adaptar à realidade política do país, sempre de forma contextualizada com os demais fatores sociais que, em maior ou menor escala, influenciaram na formação do sistema partidário. É importante que as propostas de reforma do sistema eleitoral visando determinado efeito no sistema partidário levem em consideração a divergência entre os autores citados, na tentativa de se afastar de testes pouco precisos quanto aos efetivos resultados.

352. NOHLEN, Dieter. Sistemas electorales y partidos políticos. México: Fondo de Cultura Económica, 2004, p. 128.

353. NOHLEN, Dieter. Sistemas de partidos. In Diccionario electoral. San José: Instituto Interamericano de Derechos Humanos, 1989, p. 648.

354. LIPSON, Leslie. The two-party system in British Politics. ASPR. V.47, 1953, p. 337. Apud: SILVA, Luís Virgílio Afonso da. Sistemas eleitorais. São Paulo: Malheiros, 1999, p. 115. 
Constata-se do diálogo mencionado que mesmo que se estabeleçam arranjos eleitorais em respeito ao princípio proporcional, pode ser que os eleitores identifiquem-se com apenas dois partidos relevantes ao sistema, configurando assim um quadro bipartidário, sem que o princípio representativo tenha sido violado. Por outro lado, pode-se estabelecer um sistema majoritário simples, em circunscrições uninominais divididas pelo país e, ainda assim, em cada circunscrição os eleitores votarem em partidos diferentes. Nessa ocasião ocorreria um pluripartidarismo nacional, não obstante a adoção de arranjos majoritários.

É importante que a representação segundo o princípio previamente determinado tenha sido oportunizada pelo sistema, mas o resultado diverso das urnas não o torna mal sucedido, eis que cumpriu com a sua função principal. Não é incorreto esperar de determinado sistema eleitoral a configuração de um sistema partidário correspondente, contudo, não se pode colocar tal objetivo como a sua finalidade principal. Não se pode, ainda, prever que em todas as situações haverá relação direta entre eles, tendo em vista que em determinados contextos sociais e políticos a influência pode ser maior ou menor.

Dessa forma, se por um lado os sistemas eleitorais não possuem influência determinante sobre os sistemas partidários, também não se pode admitir que os sistemas eleitorais devam ser escolhidos aleatoriamente, sem qualquer análise acerca dos rumos que o sistema eleitoral pode atribuir ao sistema partidário. Há um ponto de equilíbrio entre a causalidade determinante e a ausência total de influência dos sistemas eleitorais sobre os sistemas de partidos.

Nessa perspectiva, os elementos teóricos trazidos no presente artigo fazem sentido como ponto de partida na discussão sobre a escolha do sistema eleitoral da seguinte maneira: (i) é preciso determinar qual é o princípio representativo valorado pela sociedade - para que o sistema eleitoral cumpra a sua função precípua de assegurar autentica representação popular; (ii) verificar quais são os efeitos políticos esperados do sistema eleitoral com relação ao sistema partidário, equilibrando-os com o princípio representativo resguardado; (iii) os enunciados sociológicos são uteis em um primeiro momento para verificar qual sistema eleitoral possuiria a tendência de gerar os efeitos esperados sobre o sistema partidário; (iv) após isto, é necessário verificar como devem ser combinados e delimitados os elementos que compóem o sistema eleitoral visando os resultados pretendidos; (v) é necessário, ainda, buscar equilibrar os resultados pretendidos mediante ajustes em algum dos elementos, tal como a adoção de cláusula de barreira, tamanho das circunscrições ou fórmula mista, por exemplo; (vi) verificar se o contexto social e político oferece condições para ocorrência dos resultados pretendidos com a adoção de determinado sistema eleitoral; (vii) verificar como realmente funciona o sistema partidário, mediante identificação de partidos relevantes, não apenas pela avaliação numérica.

\section{Referências}

BALDINI, Gianfranco. PAPPALARDO, Adriano. Elections, electoral systems and volatile voters. Hampshire: Palgrave Mcmillan, 2009.

CARTER, Elisabeth. FARRELL, David. M. Electoral systems and election management. In: NORRIS, Pippa. LeDUC, Lawrence. NIEMI, Richard G. Comparing democracies elections and voting in the 21 Century. Los Angeles: Sage, 2010. 
Disponível em: <http://www.electionguide.org/election.php?ID=1421>. Acesso em 23. nov. 2015.

Disponível em: <http://www2.camara.gov.br/deputados/liderancas-e-bancadas/bancada-na-posse $>$. Acesso em: 12, out. 2015.

DUVERGER, Maurice. Los partidos politicos. México: Fondo de Cultura Económica, 2006.

GRUNBERG, Gérard. HAEGEL, Florence. Le bipartisme imparfait en France et en Europe. Revue internationale de politique comparée, 2007/2 Vol. 14. Disponível em: <http:// www.cairn.info/revue-internationale-de-politique-comparee-2007-2-page-325.htm >. Acesso em 25 . nov. 2015.

HANCOCK, Donald. M. Politics in Europe. Washington, D.C: CQ Press, 2007.

HESSE, Konrad. Elementos de direito constitucional da República Federal da Alemanha. Porto Alegre: Sergio Antonio Fabris, 1998.

INTERNATIONAL INSTITUTE FOR DEMOCRACY and electoral assistance (IDEA). Disponível em: <http://www.idea.int/esd/type.cfm?electoralSystem=STV >. Acesso em 23. nov. 2015.

. Disponível em: <http://www.idea.int/esd/glossary.cfm\#List\%20PR>. Acesso em 23. nov. 2015.

LIJPHART, Arend. Democracies: patterns of majoritarian and consensus government in twenty one countries. New Haven: Yale University Press, 1984.

. Electoral systems and party systems $:$ a study of twenty-seven democracies, 1945-1990. New Yorque: Oxfor University Press, 1998.

. Modelos de democraciaः desempenho e padrões de governo em 36 países. 2. ed. Rio de Janeiro: Civilização Brasileira, 2008.

LIPSON, Leslie. The two-party system in British Politics. ASPR. V.47, 1953. Apud: SILVA, Luís Virgílio Afonso da. Sistemas eleitorais. São Paulo: Malheiros, 1999.

MICHELS, Robert. Trad. TREVISAN, Hamilton. Os partidos políticos. São Paulo: Senzala, 1969.

NICOLAU, Jairo Marconi. Multipartidarismo e democracia. Rio de Janeiro: Fundação Getúlio Vargas, 1996.

NOHLEN, Dieter. Os sistemas eleitorais‡ o contexto faz a diferença. Lisboa: Livros Horizonte, 2007. 
. Sistemas de partidos. In Diccionario electoral. San José: Instituto Interamericano de Derechos Humanos, 1989.

. Sistemas electorales del mundo. Madri: Centro de estúdios Constitucionales, 1981.

. Sistemas electorales y partidos politicos. 3, ed. México: Fondo de Cultura Económica, 2004 .

NORRIS, Pippa. Electoral engineering: voting rules and political behavior. Cambridge University Press: Cambridge, 2004.

OSTROGORSKI, Moisei. La démocratie et l'organisation des partis politique. Paris: Calmann-Levy, 1903.

PACTET, Pierre. Institutions politiques droit constitutionnel. Paris: Armand Colin, 2002.

PERES, Paulo. Revisitando a teoria geral dos partidos de Maurice Duverger. Revista Brasileira de Informação Bibliográfica em Ciências Sociais - Anpocs 68.2. São Paulo, 2009.

PORTO, Walter Costa. Dicionário do voto. Brasília: UnB, 2000.

. O voto no Brasil: da Colônia à 6a República. Rio de Janeiro: TopBooks, 2002.

RAE, Douglas W. The political consequences of electoral laws. New Haven: Yale University Press, 1967.

. Leyes electorales y sistema de partidos politicos. Madrid: Citep, 1997.

SARTORI, Giovanni. A teoria da representação no Estado representativo moderno. Belo Horizonte: Revista Brasileira de Estudos Políticos. n.22, 1962.

. Engenharia constitucional: como mudam as constituições. Brasília: UnB, 1996.

Partidos y sistemas de partidos. 2. ed. Madrid: Alianza Editorial, 2005.

Teoria democrática. Lisboa: Fundo de Cultura, 1965.

SILVA, Luis Virgílio Afonso da. Sistemas eleitorais. São Paulo: Malheiros, 1999. 
Recebido em: 18/12/2015

Aceito em: 20/03/2016

\section{Como citar}

RANGEL, Bruno. Sistemas eleitorais e partidários: Duverger, Sartori e Nohlen. Ballot. Rio de Janeiro: UERJ. Volume 2 Número 1 Janeiro/Abril 2016. pp. 136-157. Disponível em: [http://www.e-publicacoes.uerj.br/index. php/ballot]

\section{c) (i) (2)}

A Revista Ballot está licenciada sob uma licença Creative Commons Atribuição - Não Comercial - Compartilha Igual 3.0 Não Adaptada. 